\title{
Percepção da População de Juazeiro do Norte-CE, acerca das Mudanças Inerentes à Intralogística Advindas da Indústria 4.0
}

\author{
Thainara Clara Xavier Bezerra ${ }^{1}$; Alyne Leite de Oliveira ${ }^{2}$; Antonio Raniel Silva Lima ${ }^{3}$
}

\begin{abstract}
Resumo: Mesmo com a adequação das organizações ao cenário da Indústria 4.0, os profissionais também necessitam se adaptar e entender o seu real significado, pois diante desse universo totalmente automatizado, os processos surgirão e outros deixarão de existir. Desse modo, o trabalho em questão pautou-se no objetivo de verificar a percepção da população da cidade de Juazeiro do Norte-CE acerca das mudanças inerentes à intralogística advindas da indústria 4.0. Para alcance dos resultados foi aplicado um questionário com 15 perguntas fechadas, por meio da plataforma online do Google formulários. O estudo ora apresentado caracterizou-se pelo método survey, objetivo descritivo e abordagem quantitativa. Com uma realidade como a Indústria 4.0, as pessoas precisam estar preparadas para essa nova era, pois notável que não é uma tendência e sim uma realidade. É viável que o entendimento da população seja adequado para a nova realidade, porém diante da pesquisa realizada, pôdese observar que ainda se necessita muito a ser estudado e levantando acerca da Indústria 4.0 e a Intralogística. Mesmo com a adequação das organizações a essa nova era 4.0, os profissionais também necessitam se adaptar e entender o seu real significado, pois diante desse universo totalmente automatizado, alguns processos surgirão, e já outras deixarão de existir.
\end{abstract}

Palavras-chave: Indústria 4.0. Intralogística. Automatização.

\section{Perception of the Juazeiro do Norte's Population about Changes Inherent to Intralogistics Advised by the Industry 4.0}

\begin{abstract}
Even with the adequacy of organizations to the industry 4.0 scenario, their own results are adequate and understood for their real meaning, because it is ahead of the fully automated universe, the processes of expression and others ceased to exist. Thus, the work in question is no longer seen in the city of the city of Juazeiro do Norte$\mathrm{CE}$ on the intralogistics changes inherent in the industry 4.0. To obtain results of the results a questionnaire with 15 closed questions was applied, through the online platform. The study is a document by survey method, objective describes and quantitative method. With a reality like Industry 4.0, how people need to be prepared for this new era, because they are not a trend but a reality. It is feasible that the understanding of the community is adequate for a new reality, already being researched on the industry 4.0 and an intralogística. Even with the appropriateness of organizations to this new era, 4.0, the processes have also been diverted and understood for their real meaning, since they are subordinate to the fully automated universe, some processes have stretched, and have ceased to exist.
\end{abstract}

Keywords: Industry 4.0. Intralogistics. Automation.

\footnotetext{
${ }^{1}$ Graduanda do curso de Administração do centro Universitário Doutor Leão Sampaio-thayxb@gmail.com.

2 Professora Orientadora do Centro Universitário Doutor Leão Sampaio, especialista em Logística Empresarialalyneoliveira@leaosampaio.edu.br.

3 Professor co-orientador do Centro Universitário Doutor Leão Sampaio/UniLeão e da Faculdade Vale do Salgado/FVS. 


\section{Introdução}

Em um cenário de mudanças constantes, as empresas utilizam-se de métodos e técnicas que as mantenham competitivas, gerando resultados positivos e sem altos custos, sendo necessária a inovação para um impacto maior das mesmas e a busca pelo sucesso. Crossan e Apaydin (2010), relatam que a inovação é explicada como a produção ou implantação de algo novo por meio da criação, assimilação ou exploração de uma novidade que gere valor à empresa.

Para preencher essa necessidade de mudanças, as organizações percebem a necessidade de adesão a tecnologias, e desse modo a logística das organizações é restruturada. Devido ao avanço da tecnologia, a qual a automação ganha força e espaço no meio organizacional. De acordo com Groover (2011), automação é um processo sem a atuação direta de um ser humano, processo esse executado por uma máquina, que na maioria das vezes tem o humano na sua supervisão.

Diante desse contexto relatado surgem os seguintes questionamentos? A população está preparada para a indústria 4.0? Qual a percepção dos pesquisados quanto à intralogística no tocante ao nível de automação apresentado pela indústria 4.0?

Assim, o objetivo geral do presente trabalho é analisar a percepção da população a respeito da Indústria 4.0 e da Intralogística. Para tanto, os objetivos específicos são: Conceituar intralogística e indústria 4.0; Analisar a importância das mesmas; Identificar o impacto da ineficiência da intralogística para a organização.

O tema abordado levanta informações relevantes para análise e viabilidade no que diz respeito a intralogística e o nível de automação da indústria 4.0. A pesquisa pode fornecer informações importantes para o meio acadêmico e gestores da região através da análise feita. A região está em grande crescimento e precisa de estudos para nortear até mesmo as novas empresas que surgem

\section{Intralogística}

Segundo Ballou (2001), a logística compreende todas as atividades importantes para a disponibilização de bens e serviços aos consumidores quando e onde estes quiserem adquirilos. Essas atividades incluem planejamento, transporte, armazenagem e etc. De acordo com 
Ballou (2014), as atividades de transporte, estoques e comunicações iniciaram antes mesmo da existência de um comércio ativo entre regiões vizinhas. Hoje as empresas devem realizar estas mesmas atividades como uma parte essencial de seus negócios, a fim de prover seus clientes com os bens e serviços que eles desejam.

Para Bulgacov (2006), os métodos logísticos são especificados por reunir processos sob uma mesma ótica, em que todas as atividades de deslocamento, movimentação e controle de materiais e de pressão são necessárias para que o produto ou serviço seja disponibilizado de forma adequada ao cliente. Quanto mais integrado é o processo logístico menor é a possibilidade de as mesmas atividades repetirem-se no decorrer da cadeia de abastecimento.

Olívio (2013) confirma que a logística trata de planejamento, organização, controle e realização de tarefas associadas à armazenagem, transporte e distribuição de bens e serviços, que a mesma é existente desde os tempos mais antigos, os líderes militares desde os tempos bíblicos já se utilizavam da logística.

De acordo com Fleury et al. (2012), um grupo de mudanças econômicas vem transformando a visão empresarial sobre logística, que passou a ser vista não mais como uma simples atividade operacional, um centro de custos, mas sim como uma atividade estratégica, uma ferramenta gerencial, fonte potencial de vantagem competitiva.

A intralogística ou logística interna de uma organização é todo o processo de entrada, armazenagem, e saída, que no caso é a entrega da mercadoria ao cliente na maioria das vezes, ou seja, todo o processo dentro da organização, tendo como foco o melhoramento no fluxo dos materiais.

Meirim (2017) afirma que a intralogística tem muitos benefícios para as empresas quando as mesmas têm esse foco na logística interna da sua própria organização, como tem muitos desafios para os gestores, sendo necessários e importante a busca continua de verificação dos processos internos implantados.

Carillo (2017) menciona que as empresas estão investindo na intralogística ou logística interna como é chamada para a tentativa de racionalizar os processos logísticos, devido a sua eficiência nos níveis de serviços ao cliente e o seu gasto. Relata também que a alguns tempos atrás desenhar uma operação intralogística era uma mera questão de aposta ou conveniência, e que não utilizavam uma boa instalação da mesma, sendo eficaz onde obteria economia de recursos e a satisfação dos clientes.

Para Teixeira (2012), a logística interna é todo o desenvolvimento de recebimento, agrupamento, controle e distribuição dos insumos a serem utilizados, dentro de uma organização, para futuras vendas, afirma ainda que se utilizada a logística interna nas indústrias 
é um fator essencial para as mesmas obterem total eficiência e aumentar a sua produtividade. Segundo a Revista Intralogística (2013), a empresa Célere foi a primeira empresa especializada na intralogística do Brasil, possuindo profissionais experientes, para a implementação da mesma.

Lima Jr (2017) relata que na intralogística não é só realizável as atividades especificas, está incluída também nos softwares e banco de dados, ampliando no seu avanço da produtividade organizacional através desses sistemas tecnológicos. Rodrigues (2018) afirma que dado o momento que se toma a decisão de entrar a fundo na análise de problemas e ineficiências dentro das rotinas e dos processos de uma unidade logística é que se começa a descobrir o quanto há de problemas que poderiam ser evitados e que causam impacto negativo nos clientes, bem como o quanto há de desperdícios e paradigmas que não recebem a devida atenção para serem eliminados.

\section{Intralogística X Indústria 4.0}

A revolução industrial foi a substituição do artesanato para as máquinas e indústrias, com isso obteve-se uma maior produção, uma mão de obra mais econômica. Foi a partir da revolução industrial que se obteve um pulo no crescimento econômico, e uma melhora na qualidade de vida.

Para Meirim (2017), com o passar dos tempos, a revolução industrial foi sendo modificada, devido ao avanço das tecnologias. A Primeira Revolução Industrial surgiu na Inglaterra no final do século XVIII início do século XIX, onde a mesma foi marcada principalmente pela chegada da máquina à vapor na indústria têxtil e locomotiva, nesse período a produção deixou de ser artesanal e passou a ser manufaturada, e sua produção passou a ser em larga escala.

A Segunda Revolução Industrial iniciou no final do século XIX e prolongou até o século $\mathrm{XX}$, este período foi caracterizado pelo emprego do aço, a utilização da energia elétrica e dos combustíveis derivados do petróleo, a invenção do motor, a locomotiva a vapor e o desenvolvimento de produtos químicos (MEIRIM, 2017).

A Terceira Revolução Industrial teve início no final da década de 70, e mudou a configuração do sistema de produção, agora firmado na tecnologia, na robótica, na telecomunicação, essa foi denominada de Revolução Técnico-Científica. caracteriza-se, pela descoberta da energia nuclear, e do uso da informática. A indústria 4.0 ou a quarta revolução 
industrial é a automação industrial, que vai revolucionar o mundo das indústrias, devido a sua total automação os profissionais precisam desenvolver um perfil multidisciplinar, para então conseguir acompanhar esse mundo automatizado (MEIRIM, 2017).

Fraga e Cardoso (2016) definem a Indústria 4.0 como um avanço nas organizações, que surgiu na Alemanha, tendo um conjunto de termos usados pelos profissionais como "fábricas inteligentes", "A internet das coisas industriais" ou "Produção Avançada", servindo para ajudar atingir os objetivos empresariais. Magnus (2017) menciona que as adições de benefícios para as empresas em relação a Indústria 4.0 são enormes, tanto em relação ao processo de produção e gerenciamento da indústria quanto na relação com o cliente, pois um das características principais das indústrias 4.0 é a velocidade, e que essa dinâmica será marcada pela agilidade na informação, inovação e o retorno da empresa ao mercado de trabalho.

De acordo com Hahn (2016), a aplicação da Indústria 4.0 fornece grandes oportunidades para os empreendedores que são da área tecnológica, onde vai revolucionar esse ramo como nunca visto, e que muitas coisas necessárias para a implantação da indústria 4.0, ainda precisa ser desenvolvido e aperfeiçoado. Marchioro e Mezacasa (2018) relatam que na indústria 4.0 sua aplicação provavelmente provocará mudanças importantes nas práticas de sua empresa, bem como dos colaboradores, afirmando ainda que é um trajeto sem volta onde todos ganham, mas requer dedicação, flexibilidade e preparo. Klaus (2016 apud PASQUALOTTO; BUBLITZ, 2017) afirma que a Indústria 4.0 ocasionará um certo transtorno no mercado de trabalho, como também aos modelos de negócios nos próximos anos, com várias mudanças já ocasionada pela chegada da indústria 4.0 .

Segundo Blanchet et al. (2014), os seres humanos dividem a empresa com os robôs e o mundo da automatização, trabalhando juntos com sensores inteligentes, o mesmo diz ainda que os robôs podem incluir as funções de produção, logística e gestão de escritório, podendo ser controlada de forma remota. Zuazo (2018) menciona que um estudo da Universidade de Oxford indica que $35 \%$ das ocupações no ambiente de trabalho, deverá ser automatizada, no decorrer de duas décadas, relata ainda que a robótica é um mercado que tem muito a crescer e ser investido.

\section{Automação}

Rosário (2009) define a automação como uma inclusão de conhecimento substituindo os esforços humanos, as decisões e outros pelos dispositivos no geral, sendo concebidos por 
meios da alta tecnologia. Relata ainda que por muito tempo a automação, durante muito tempo era totalmente dependente dos humanos, pois as maquinas automáticas não tinham integração entre as mesmas.

Pereira (2018) menciona que quando se fala em automação, se faz referência a utilização de ferramentas e sistemas de gestão, que possibilitam a execução automáticas de processos que anteriormente eram executados manualmente, exigindo bastante tempo e muita força humana. Relata ainda que diante disso a automação oferece agilidade, melhora a estratégia logística, facilita o gerenciamento, e tem forte impacto sobre as rotinas de trabalho.

A automação para José Filho (2012) pode também ser entendida como um acontecimento do mundo contemporâneo, marcado pela abrangência, profundidade e velocidade das inovações tecnológicas e organizacionais. E que a mesma tem transformado os processos produtivos em todos os setores da economia, trazendo profundos impactos na disponibilidade de empregos.

De acordo com Goeking (2010) uma das maiores vantagens da automação é a produção elevada, consegue produzir muito mais, em um tempo curto e sendo considerado esses produtos de boa qualidade, isso tudo com pouco auxilio humano. Uma grande outra vantagem é a utilização das maquinas no setor da produção, otimizando os processos, com o intuito de alcançar mais produtividade, como também a diminuição de energia em horários onde a mesma é mais cara. A autora cita ainda que existe uma desvantagem causada pela automação que é o aumento do desemprego.

Borracha (2012 apud SILVA et al., 2015) relata que outra desvantagem na automação é as despesas com os custos de manutenção, sendo o mesmo considerado uma despesa alta na maioria das vezes, e que esse custo alto é causado pela restrição dos profissionais aptos para a realização dessas manutenções.

\section{Metodologia}

O tipo de pesquisa adotada foi básico, de objetivo descritivo e abordagem quantitativa. Inicialmente foi realizada uma ampla pesquisa bibliográfica sobre os principais temas da presente pesquisa. De acordo com Alves (2007), a pesquisa bibliográfica é gerada através da base em fatores já desenvolvidos, como livros, artigos científicos, teses e publicações. 
Como procedimento técnico foi utilizado o levantamento (survey) junto à população de Juazeiro do Norte - CE. A população da pesquisa (população em geral, pois se trata de uma pesquisa de opinião) respondeu um questionário disparado por meio de um link disponível na plataforma Google Formulários. A coleta de dados ocorreu no período de 18 de outubro de 2018 ao dia 30 do mesmo mês e ano, sendo alcançadas respostas de 101 sujeitos. Os dados obtidos foram transferidos e estão sendo apresentados em gráficos na seção a seguir.

\section{Análise e Discussão dos Resultados}

A partir de 101 respostas da pesquisa, foram obtidos os dados com uma definição de gênero de $67 \%$ para os participantes do sexo feminino, sendo do sexo masculino apenas $33 \%$. Com uma predominação de idade na faixa de 19 a 29 anos, em seguida da faixa etária de 30 a 40 anos. O grau de escolaridade predominante foi o ensino superior incompleto, sendo $59 \%$ da população neste grau.

Gráfico 01: Noção sobre o que é Indústria 4.0.

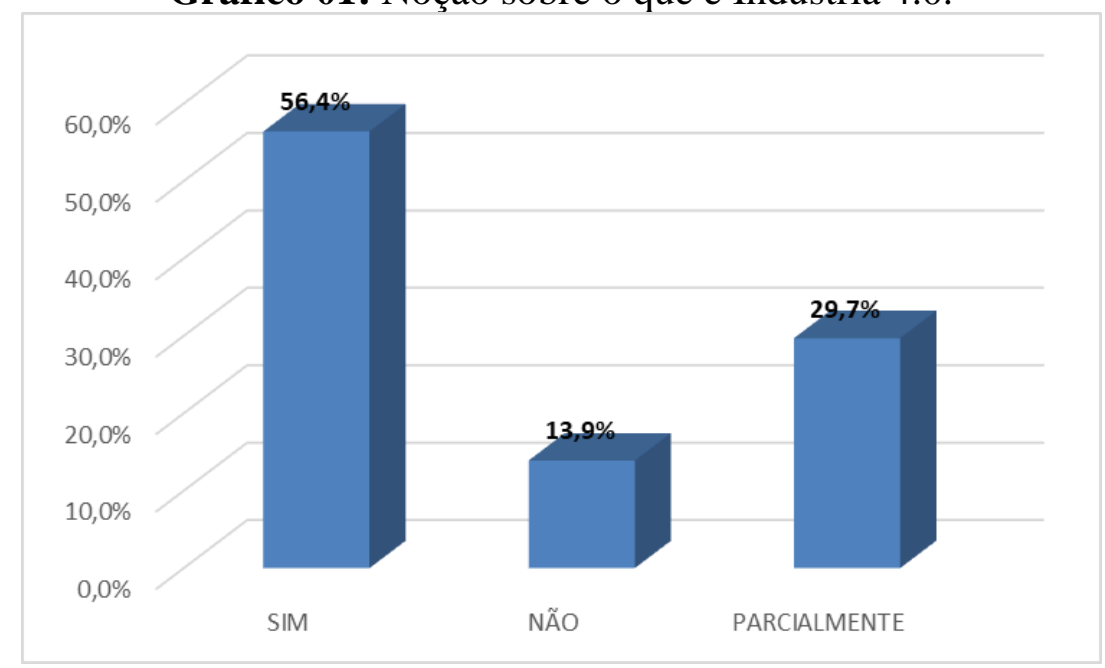

Fonte: Dados da Pesquisa 2018.

Observa-se que os dados obtidos tiveram êxito na pergunta, porém do tema em questão está com $30 \%$ para a população que já sabe moderadamente sobre a Indústria 4.0, índice considerado baixo devido a proporção do que se refere o relativo assunto. Fraga e Cardoso (2016) definem a Indústria 4.0 como um avanço nas organizações, que surgiu na Alemanha, tendo um conjunto de termos usados pelos profissionais como "fábricas inteligentes", "A internet das coisas industriais" ou "Produção Avançada". 
Gráfico 02: Escutou em algum momento sobre Indústria 4.0.

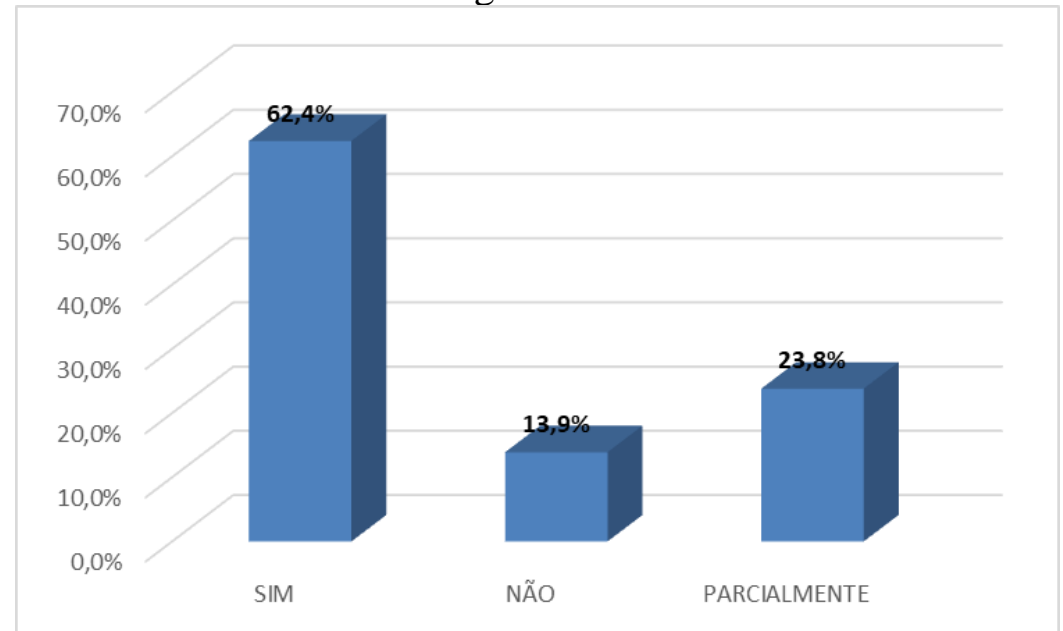

Fonte: Dados da Pesquisa 2018.

Em comparação com o Gráfico 01, no Gráfico 02, observa-se que a população em questão já ouviu falar da Indústria 4.0, porém percebe-se que houve uma queda para os que responderam saber o que era a Indústria 4.0 no gráfico 01 .

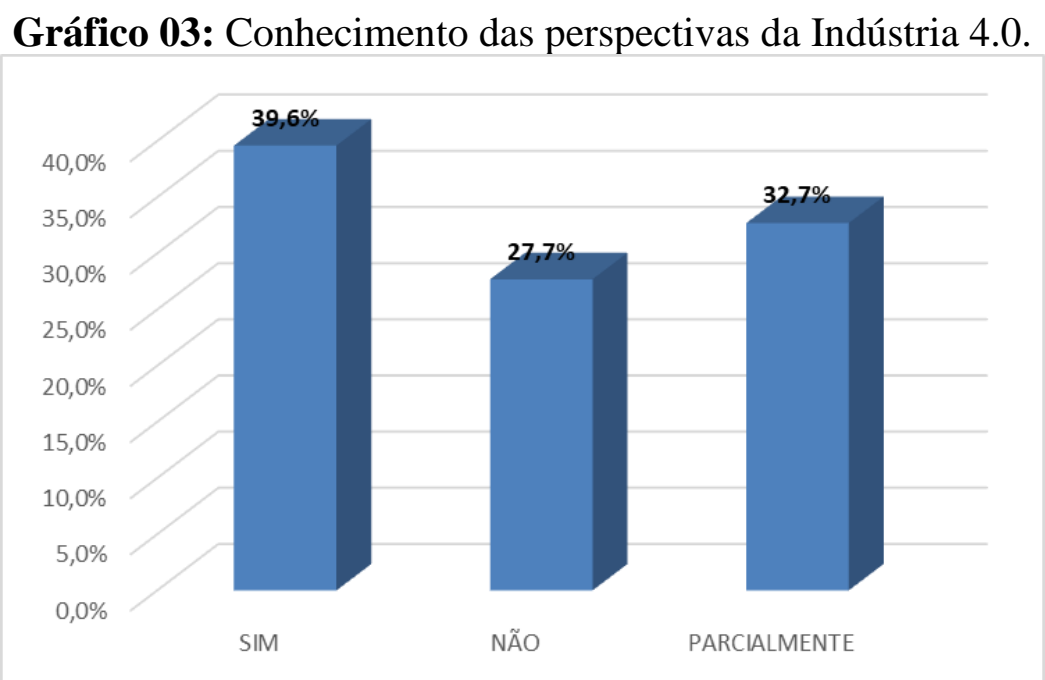

Fonte: Dados da Pesquisa 2018.

Observa-se que em relação aos gráficos 01 e 02 , a população em questão com um número maior de respostas, já ouviu falar da Indústria 4.0, porém obteve-se uma queda no conceito da Indústria 4.0 e uma queda maior agora no Gráfico 03, ficando 6,9 de diferença para "Sim" a população que conhece as perspectivas da Indústria 4.0 e conhece "Parcialmente". 
Gráfico 04: Indústria 4.0 - Tendência x Realidade.

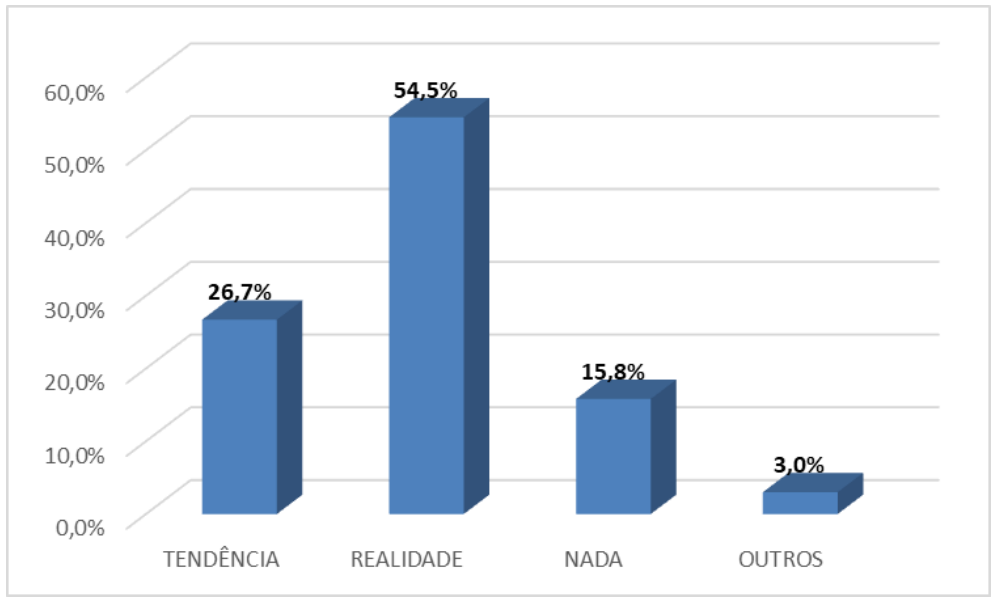

Fonte: Dados da Pesquisa 2018.

Os dados mostram que a população menor de $3 \%$ considera "Outros", porém não especificou, vindo a 15,8\% que não consideram "Nada" sobre a Indústria 4.0. De acordo com Hahn (2016), a aplicação da Indústria 4.0 fornece grandes oportunidades para os empreendedores que são da área tecnológica, onde vai revolucionar esse ramo como nunca visto.

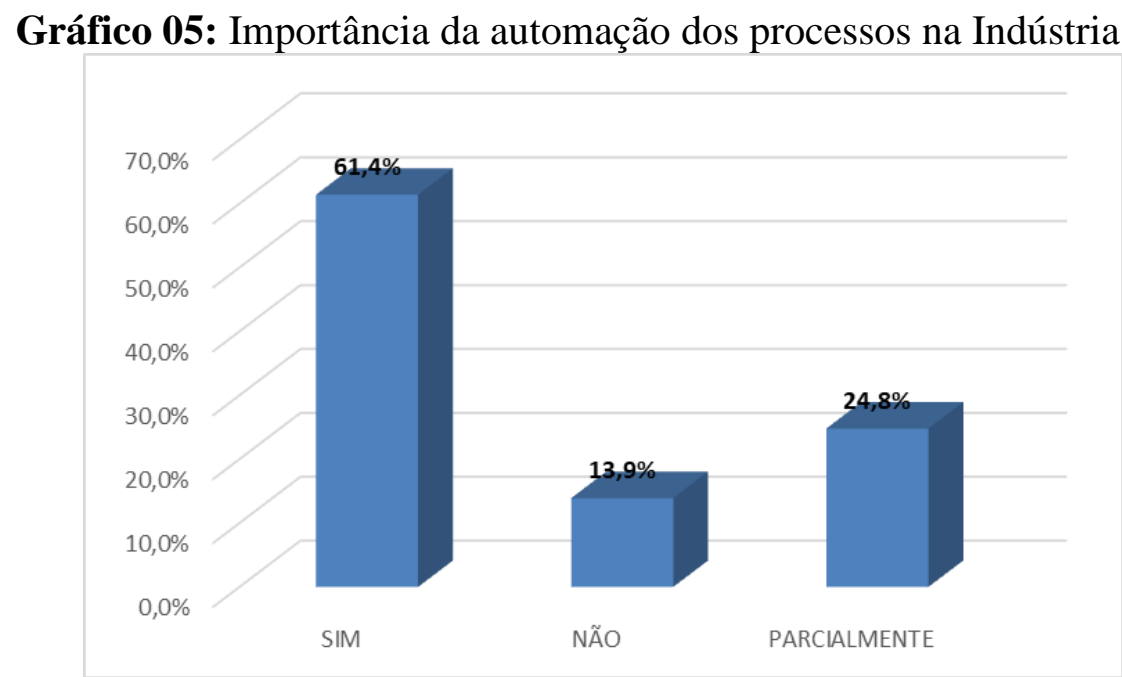

Fonte: Dados da Pesquisa 2018.

Os participantes da pesquisa responderam que consideram importante a automação nos processos da Indústria 4.0, já é um número elevado e que, Segundo Blanchet et al (2014), na Indústria 4.0, os seres humanos dividem a empresa com os robôs e o mundo da automatização trabalhando juntos com sensores inteligentes. 
Gráfico 06: Efeito da automação sobre os funcionários.

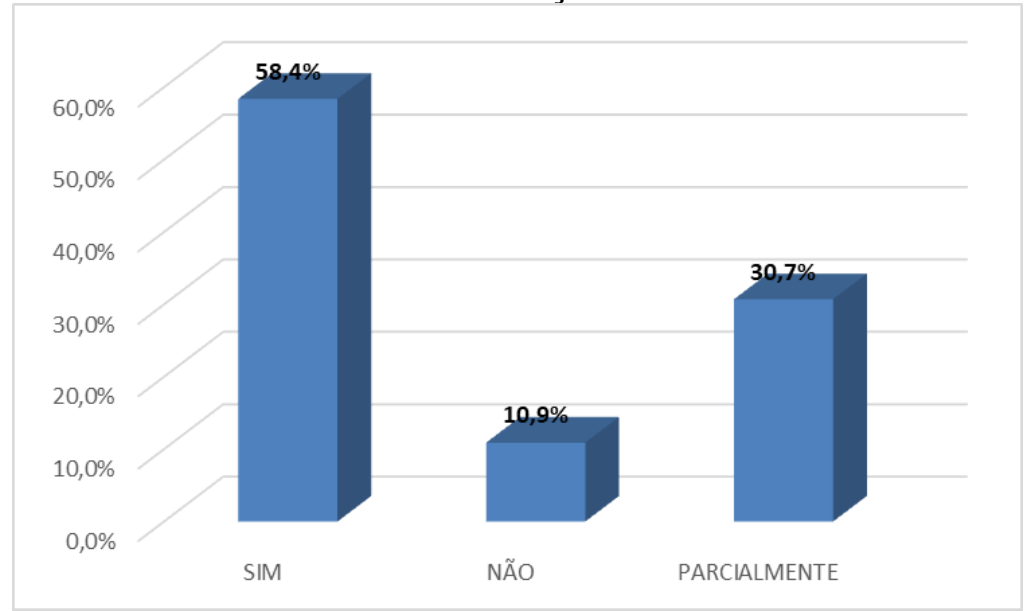

Fonte: Dados da Pesquisa 2018.

É quase metade da população em questão que considera que a automação não afetará os funcionários, sendo os dados distribuídos em "Parcialmente" e "Não", onde diante do estudo em questão, pode-se afirmar que a nova revolução irá afetar determinadas funções, sendo algumas diretamente e outras em proporções menores, mas mesmo assim vai revolucionar os métodos de trabalho.

Gráfico 07: Impacto da automação na intralogística.

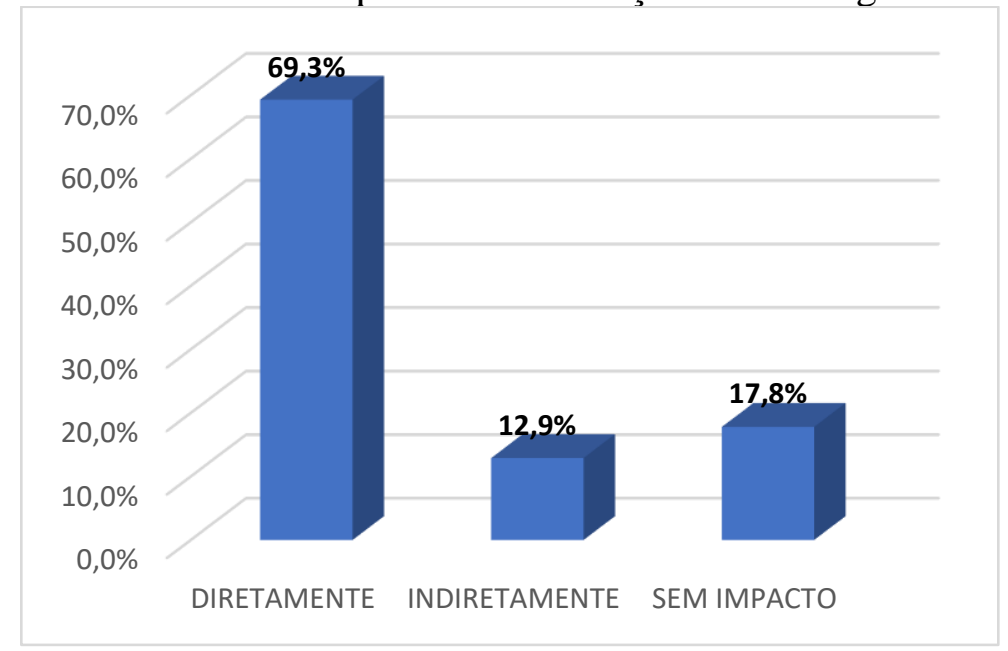

Fonte: Dados da Pesquisa 2018.

Mais da metade dos participantes relata que a automação terá impacto direto na intralogística. Lima Jr (2017) relata que na intralogística não é só realizável às atividades específicas, está incluída também nos softwares e banco de dados, ampliando no seu avanço da produtividade organizacional através desses sistemas tecnológicos. 
Gráfico 08: Importância do investimento no processo de intralogística.

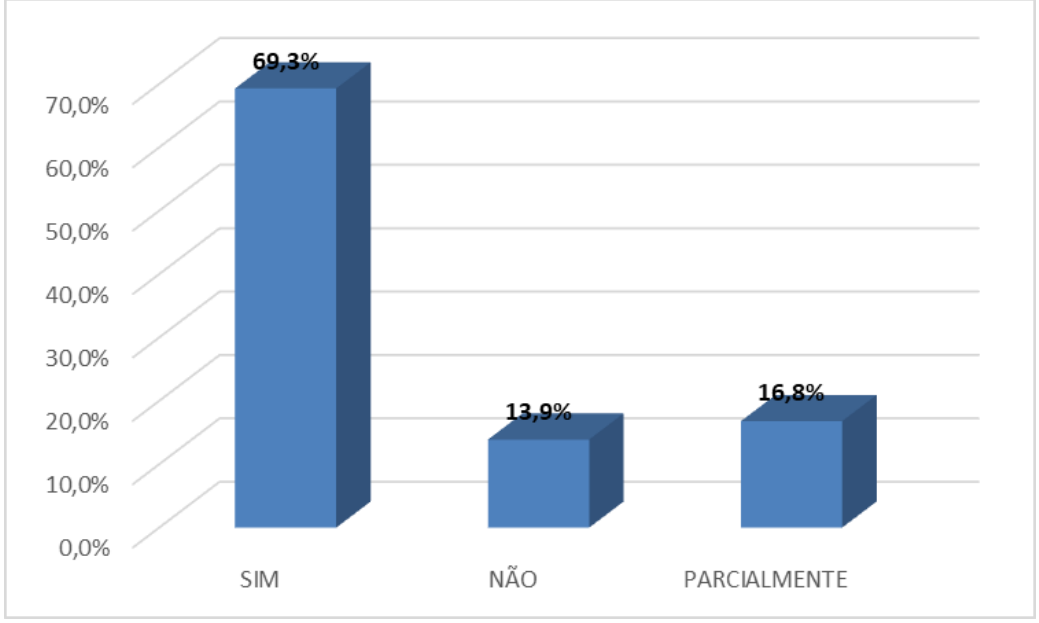

Fonte: Dados da Pesquisa 2018.

Carillo (2017) menciona que as empresas estão investindo na intralogística, ou logística interna como é chamada, para a tentativa de racionalizar os processos logísticos, devido a sua eficiência nos níveis de serviços ao cliente e o seu gasto.

Gráfico 09: Extinção de algumas profissões com a Indústria 4.0.

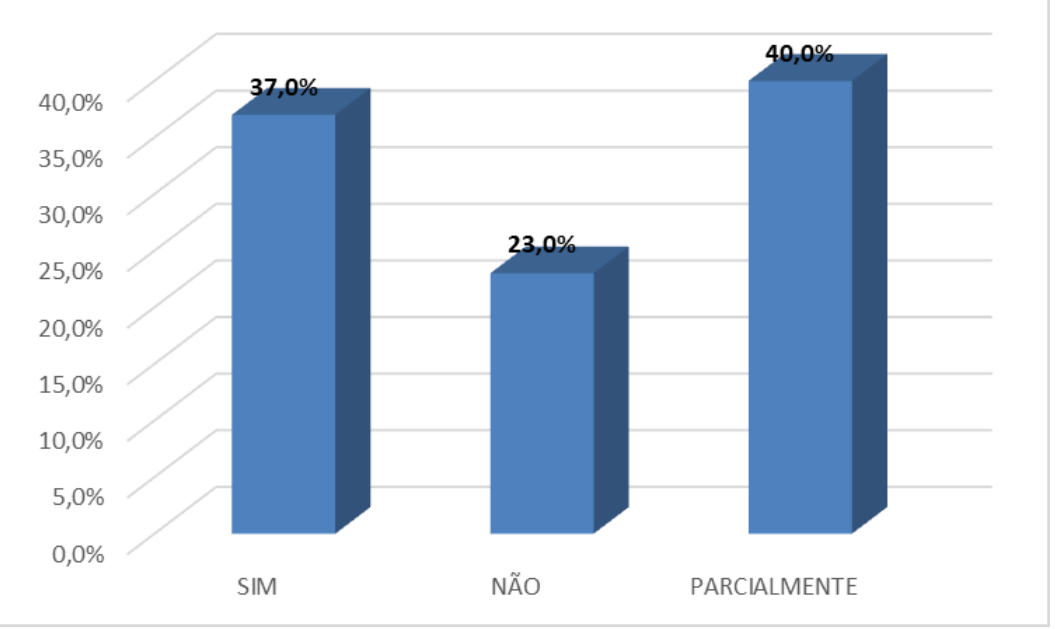

Fonte: Dados da Pesquisa 2018.

A população ficou um tanto quanto dividida diante da resposta, pois ficou entre "Sim" e "Parcialmente" para as profisssões de Auxiliar de Produção e Operador de máquinas, se serão extintas com advento da Indústria 4.0. Zuazo (2018) menciona que um estudo da Universidade de Oxford indica que 35\% das ocupações no ambiente de trabalho deverá ser automatizada no decorrer de duas décadas, relata ainda que a robótica é um mercado que tem muito a crescer e ser investido. 
Gráfico 10: Impacto da Indústria 4.0 na extinção de profissões.

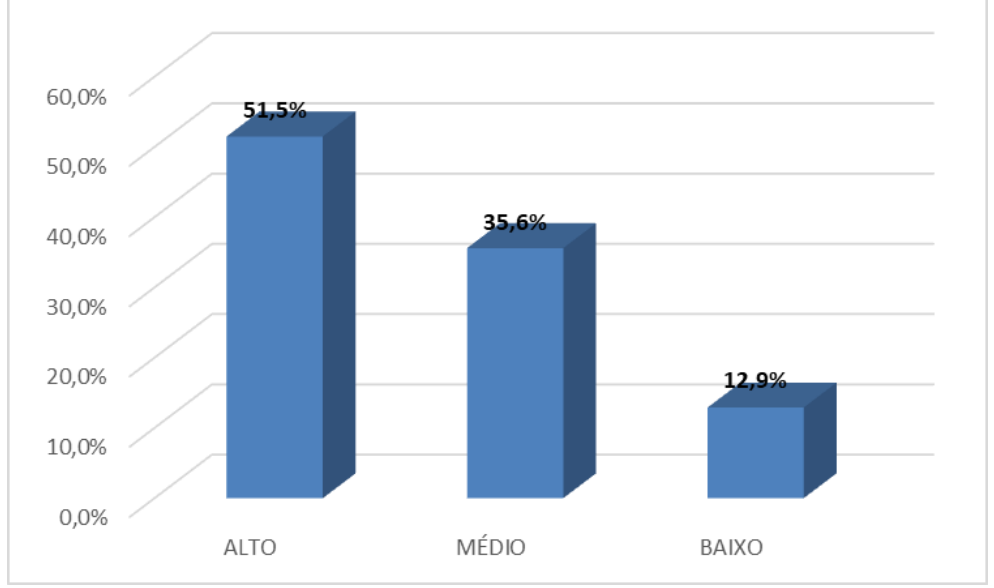

Fonte: Dados da Pesquisa 2018.

Com uma diferença de 1,5\% os participantes da pesquisa consideram que o impacto é baixo e de médio impacto para as profissões que estão sendo ameaçadas de extinção pela Indústria 4.0.

Gráfico 11: Funções da robótica no tocante ao nível de automação.

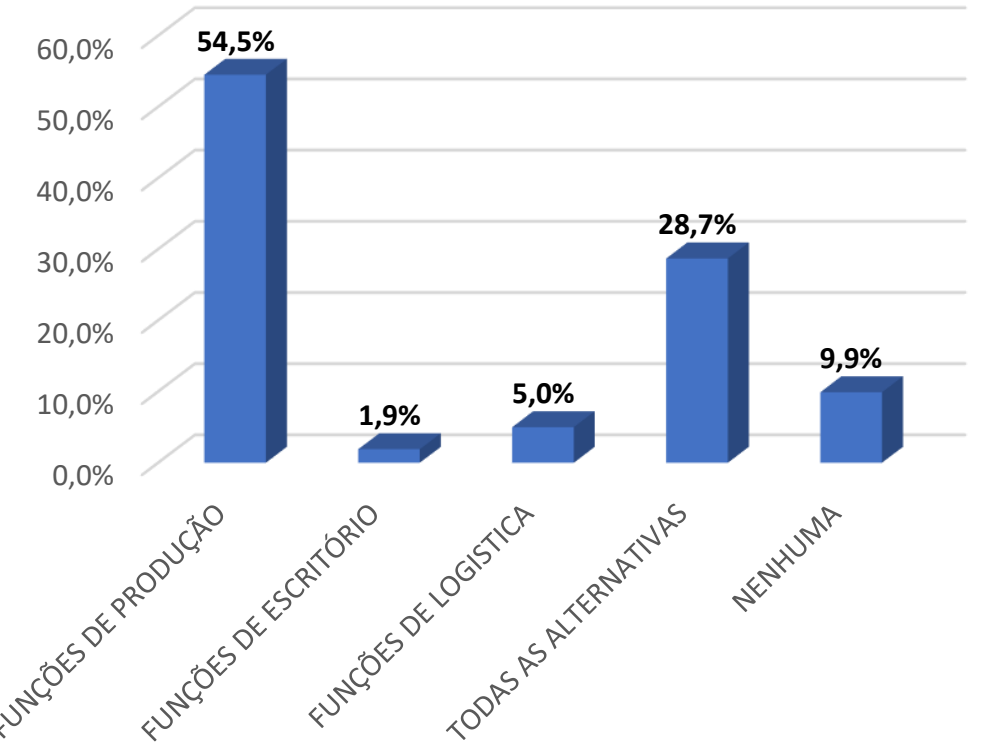

Fonte: Dados da Pesquisa 2018.

Em análise do gráfico 11, os participantes consideram que somente a função da produção pode ser exercida pela robótica, quando o autor Blanchet et al (2014) menciona que os seres humanos dividem a empresa com os robôs e o mundo da automatização, trabalhando juntos com sensores inteligentes, o mesmo diz ainda que os robôs podem incluir as funções de produção, logística e gestão de escritório, podendo ser controlada de forma remota. 
Gráfico 12: Profissões como Administração, Direito e Contábeis, precisam ser reestruturadas porque serão extintas?

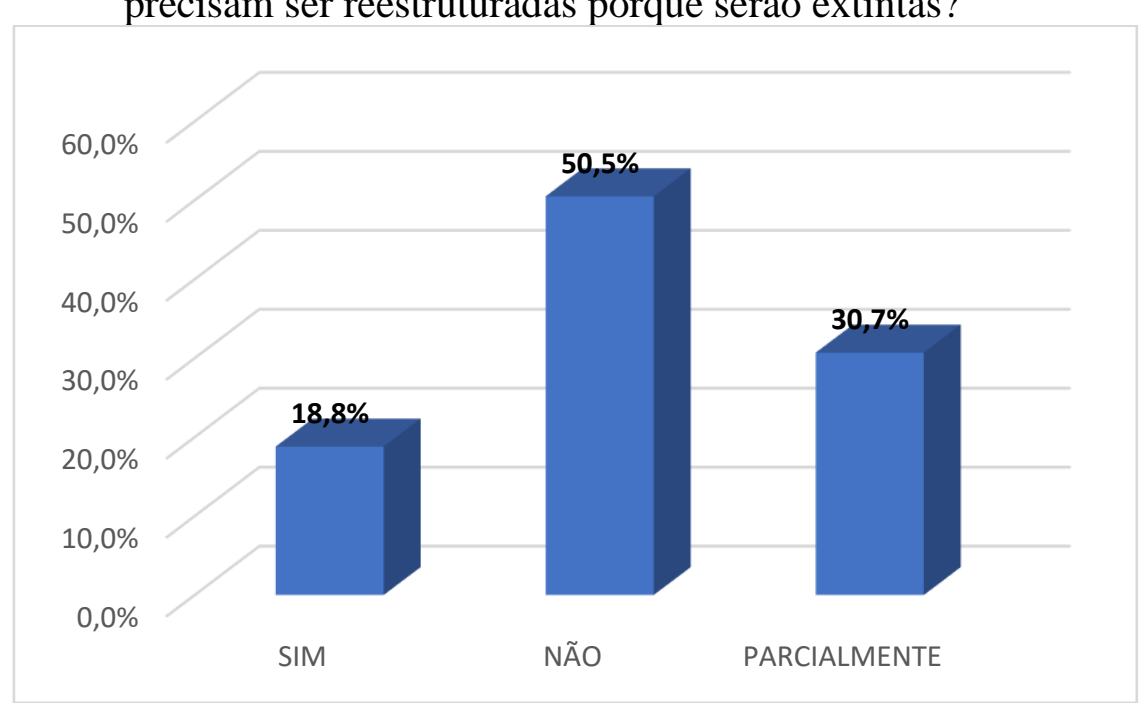

Fonte: Dados da Pesquisa 2018.

A diferença considerada grande de repostas dos participantes que acham que as profissões precisam ser restruturadas devido a Indústria 4.0. Respostas consideradas crítica devido a realidade da Indústria 4.0, observa-se a falta de conhecimento dos participantes com o real conceito do tema.

\section{Considerações Finais}

Com uma realidade como a Indústria 4.0, as pessoas precisam estar preparadas para essa nova era, pois notável que não é uma tendência e sim uma realidade. É viável que o entendimento da população seja adequado para a nova realidade, porém diante da pesquisa realizada, pôde-se observar que ainda se necessita muito a ser estudado e levantando acerca da Indústria 4.0 e a Intralogística. Mesmo com a adequação das organizações a essa nova era 4.0, os profissionais também necessitam se adaptar e entender o seu real significado, pois diante desse universo totalmente automatizado, alguns processos surgirão, e já outras deixarão de existir.

A Internet das Coisas, que viabiliza cada vez mais, as trocas de informações em tempo real, é uma das grandes responsáveis por esta nova revolução. As tarefas manuais e repetitivas já vêm sendo substituídas por mão de obra automatizada, e com a Indústria 4.0 isso tende a prosseguir. Por outro diverso lado, as demandas em análise e desenvolvimento oferecerão oportunidades para profissionais tecnicamente capacitados, com desenvolvimento 
multidisciplinar para compreender e trabalhar com a variedade de tecnologia que compõe uma fábrica inteligente.

E considerável que os profissionais de logística procurem operar na revisão contínua dos processos internos, na busca pelas oportunidades de implementação de tecnologia e automação e na constante capacitação e motivação das equipes que atuam diretamente ou indiretamente nestes processos. Vale ainda destacar que, mesmo em se tratando de processos internos, o entendimento das necessidades e expectativas dos fornecedores e clientes passa a ser fundamental para a melhoria da intralogística, sendo a colaboração uma palavra-chave neste aspecto.

A tecnologia praticamente toma conta dos processos da indústria, uma das exigências adequadas que as empresas executarão é exatamente a flexibilidade para se adaptar ao seu espaço. Isso significa que as pessoas deverão demonstrar habilidade para lidar com diferentes tecnologias e interesse no aprendizado constante em relação às novas funções que surgirão nesse horizonte. No dia a dia, isso representa a necessidade de muito estudo, pesquisa e capacitação. Os profissionais deverão cada vez mais correr em busca de conhecimento para compreender esse novo momento e estarem prontos para ele.

Esta pesquisa é capaz de fornecer informações importantes para o meio acadêmico e gestores da região, através da análise feita, como a região está em grande crescimento e necessariamente precisa de estudos levantados para nortear até mesmo as novas empresas que surgem, tanto quanto as pessoas.

\section{Referências}

ALVES, M. Como escrever teses e monografia: um roteiro passo a passo. Rio de Janeiro: Elsevier, 2007.

BALLOU, R. H. Logística Empresarial: transportes, administração de materiais e distribuição física. São Paulo: Atlas, 2014.

BALLOU, Ronald H. Gerenciamento da cadeia de suprimentos: planejamento, organização e logística empresarial. $4^{\text {a }}$ ed. Porto Alegre: Bookmann, 2001.

BLANCHET, M. Industry 4.0: the new industrial revolution. How Europe will succeed. Munique: Roland Berger Strategy Consultants Gmbh, 2014. Disponível em: https://www.rolandberger.com/publications/publication_pdf/roland_berger_tab_industry_4_0 _20140403.pdf. Acesso em: 19 mar 2018.

BULGACOV, Sergio. Manual de gestão empresarial. $2^{\text {a }}$ ed. São Paulo: Atlas, 2006. 
CARILLO, E; A Importância da Intralogistica na Produtividade, economia de recursos e melhorias dos serviços. Revista Logweb. V. 1, N. 184, P 26, 2017. Disponível em: http://www.logweb.com.br/revista/edicao-184-outubro-2017/ Acesso em: 20 mar. 2018

CROSSAN, M. M.; APAYDIN, M. (2010). A multi-dimensional framework of organizational innovation: A systematic review of the literature. Journal of management studies, 47(6), $1154-1191$.

FLEURY, Paulo Fernando (Org.) et. al. Logística empresarial: a perspectiva brasileira / 1 ed. - 15 reimpr. - São Paulo: Atlas, 2012. - Coleção COPPEAD de Administração.

GOEKING, W. Memória da eletricidade. 2010. Disponível em: https://www.voltimum.com.br/sites/www.voltimum.com.br/files/memoria_maio_10.pdf Acesso em:21. Nov. 2018.

GROOVER, M. P. Automação industrial e sistemas de manufatura. 3. ed.São Paulo, SP: Pearson Prentice Hall, 2011. Disponível em :http://feevale.bv3.digitalpages .com.br/users/publications/9788576058717/pages/_1. Acesso em: 03 jul. 2018.

HAHN, Rizzo. J. A Era da Internet Industrial e a Indústria 4.0 já estão moldando o futuro de muitos empreendedores. Saiba como aproveitar essa nova tendência. 2016. Disponível em: $<$ https://endeavor.org.br/oportunidades-industria-4_0/>. Acesso em: 20 mar. 2018.

JOSÉ FILHO, L, W. A eficácia do direito fundamental da proteção em face da automação previsto no inciso XXVII, do art. $7^{\circ}$, da Constituição Federal de 1988. 2012. Disponível em: https://jus.com.br/artigos/35702/a-eficacia-do-direito-fundamental-da-protecao-em-faceda-automacao-previsto-no-inciso-xxvii-do-art-7-da-constituicao-federal-de-1988. Acesso em: 03, nov.2018.

LIMA JR, F, O. São Várias as Tendências tecnológicas a serem aplicadas na intralogistca. Revista Logweb. V.1, N. 184, P.32, 2017. Disponível em: http://www.logweb.com.br/revista/edicao-184-outubro-2017/ Acesso em: 23 mar. 2018.

MAGNUS, T. Indústria 4.0: A Quarta Revolução Industrial. 2017. Disponível em: https://transformacaodigital.com/industria-4-0/ Acesso em: 20, out.2018

MARCHIORO, J.; MEZACASA, N. Indústria 4.0: impactos e oportunidades da evolução. Revista LogWeb. Disponivel em: http://www.logweb.com.br/artigo/industria-4-0-impactos-eoportunidades-da-evolucao/ Acesso em: 20. Agos.2018

MEIRIM, H. Mais do que Nunca se Apresenta como um Diferencial Competitivo. Revista Logweb. V.1, N. 184, P. 36-37, 2017. Disponível em: http://www.logweb.com.br/revista/edicao-184-outubro-2017/ Acesso em: 20 mar. 2018

OLÍVIO, R.L.F. Logística na cadeia de suprimentos: Técnicas, ferramentas e conceitos / São Paulo: Saint Paul Editora, 2013.

PASQUALOTTO, A de S; BUBLITZ, M. D. Desafios do presente e do futuro para as relações de consumo ante indústria 4.0 e a economia colaborativa. Revista de Direito, Globalização e 
Responsabilidade nas Relações de Consumo | e-ISSN: 2526-0030 | Maranhão | v. 3 | n. 2 | p. 62-81| Jul/Dez. 2017.

PEREIRA, C, J. Mindset de software: automação como estratégia logística. 2018. Disponível em: http://www.logweb.com.br/artigo/mindset-de-software-automacao-como-estrategialogistica/ Acesso em: 31 out. 2018

RODRIGUES, R, R. Intralogística: Igualmente importante, usualmente em segundo plano. Revista Logweb. $\mathrm{N}^{\mathrm{o}}$ 20, P 4-5.2018 Disponível em: http://www.logweb.com.br/wpcontent/uploads/2018/08/lw191_dgt20-1.pdf. Acesso em: 07. Set.2018.

ROSÁRIO, M, J. Automação Industrial. São Paulo: Baraúna, 2009.

SILVA, A. L. E. et al. Proposta de automação industrial em uma empresa fabricante de borrachas escolares. Revista GEINTEC-ISSN: 2237-0722. Aracaju/SE. Vol.8, n.1, p.41594172, jan/fev/mar - 2018 .

ZUAZO, P. Automatização das profissões torna a robótica um campo fértil no mercado de trabalho. Disponível em : https://extra.globo.com/noticias/educacao/profissoes-desucesso/automatizacao-das-profissoes-torna-robotica-um-campo-fertil-no-mercado-de-trabalho22272952.html Acesso em 20 Ago.2018.

\section{Como citar este artigo (Formato ABNT):}

BEZERRA, Thainara Clara Xavier; OLIVEIRA, Alyne Leite de; LIMA, Antonio Raniel Silva. Percepção da População de Juazeiro do Norte-CE, acerca das Mudanças Inerentes à Intralogística Advindas da Indústria 4.0. Id on Line Rev.Mult. Psic., 2019, vol.13, n.43, p. 717-732. ISSN: 1981-1179.

Recebido: 30/11/2018;

Aceito: 06/12/2018 